\title{
The Impact of Learning Organizations Dimensions on the Organisational Performance: An Exploring Study of Saudi Universities
}

\author{
Abdulrahim Zaher Meshari ${ }^{1,2}$, Majed Bin Othayman ${ }^{1,2}$, Frederic Boy $^{1}, \&$ Daniele Doneddu \\ ${ }^{1}$ School of Management, Swansea University, Swansea, United Kingdom \\ ${ }^{2}$ Business School, King Khalid University, Abha, Kingdom of Saudi Arabia \\ Correspondence: Frederic Boy, School of Management, Swansea University, Swansea, United Kingdom.
}

Received: November 2, 2020

Accepted: January 13, 2021

Online Published: January 25, 2021

doi:10.5539/ibr.v14n2p54

URL: https://doi.org/10.5539/ibr.v14n2p54

\begin{abstract}
The education sector is crucial to any nation committed to building future human capital. The Higher Education sector in the Kingdom of Saudi Arabia (KSA) is at the centre of transforming the nation's future in a radical move to end oil-dependency. But this is only possible if universities make a decisive change and start working as learning organisations in all employee's levels. The present study investigates the direction of higher education in becoming learning organisations. We collected data from 840 staff members in 20 public Saudi universities. We designed a questionnaire exploring the seven dimensions of learning organisation found in the literature. Regression analyses were used to assess the impact of those dimensions on the organisational performance. Results showed that universities that adhered most to the learning organisation principles demonstrated a better organisational performance, particularly concerning research and knowledge performance. We recommend that universities should (1) use change agents to help transform effectively and meet rising demands and (2), promote continuous learning for all employees to increase productivity.
\end{abstract}

Keywords: higher education, learning organsation, organsation performance.

\section{Introduction}

The global economic environment is undergoing drastic changes as knowledge substitutes physical capital as the foundation for current and future wealth (Song et al., 2009). Knowledge in biotechnology, information technology, and other innovative technologies which have shaped the way people live and do businesses (Cosgrove \& Loucks, 2015). As the need for knowledge has become so paramount, the demand for university knowledge is also rising. Globally, the impact of higher education on social and economic development increases annually, and this is projected to continue throughout the century. University education is a centre of knowledge and its application (Boguslavskii, \& Neborskii 2016). This is because a university forms the breeding ground of the innovations and skills meant to improve the lives and solve problems affecting people. According to UNESCO, university education creates harmony and a clear link between the development of the community and education (Boguslavskii, \& Neborskii 2016). OECD states that the best way to enhance productivity growth and create highly paid employment is through investment in knowledge creation (Nielsen et al., 2011).

Although universities have for long been the main source of knowledge and continue to be, they face major challenges and need to adapt, just like other actors in a volatile market (Song et al., 2018). Around the world, numbers of policies and programs have been set up in support of the higher education sector. For example, since 1983, the US introduced more than one rating system for institutions of higher learning which indicates how much a college performs concerning different aspects of knowledge and education (Hazelkorn, 2013). This move started more than a century ago when Charles W. Eliot, the influential president of Harvard University, spearheaded an amendment of the existing higher education curriculum (Geiger, 2019). This early reform was meant to create efficiency and answer questions concerning the cost of degree courses. The National Institutional Ranking Framework (NIRF) and the National Assessment Accreditation Council (NAAC) (Yeravdekar \& Tiwari, 2016) in India are other instances of efforts made to improve university education. Such policies and measures enhance and harness the comprehensive performance of university education (Saifulhafizi, 2014).

Although learning institutions exist in the same environment as other businesses, their main purpose is not to make profits, but rather to teach and foster research. This has forced these institutions to adopt several measures which set them apart from their rivals. In the bid to remain competitive, universities have been using various strategies including restructuring and on job training programs (Imam et al, 2013). According to Al-Hemyari 
(2019), the performance and quality of universities are important to the success of the institution both in short term and long-term. A culmination of the policy measures and management strategies are on track to enhancing research and knowledge performance, but does not make the institution a "learning organisation": an organisation that helps employees engaging into continuous learning, and create the conditions for knowledge to be shared among the actors (Saifulhafizi, 2014; Goh, 1998).

\subsection{The Higher Education (HE) Sector in the KSA}

In order to comprehensively understand higher education in Saudi Arabia, it is essential to start from the early establishment of higher education sector in the country. The ministry of education was started in 1954 to manage and oversee the existing educational institutions in Saudi Arabia. A considerable number of students willing to undergo higher education were forced to move abroad (Alshuwaikhat et al., 2016). This prompted the government to establish the King Saud public University in 1957. Although students were only male, the establishment of King Saud University marked the start of the contemporary higher education in the Kingdom. The Kingdom now has more than 50 public and private institutions of higher education in the nation. In 2018, the country now boasts having 21 universities ranked among the top 100 in the Arab region (Altbach, Reisberg, Salmi, \& Froumin, 2018).

The ministry of education has been receiving, over the years, a constant flow of funding from the national government. As a part of this funding, in the year 2005, the King Abdullah Scholarship program led to the education of hundreds of students in foreign nations including Canada, the United Kingdom, Australia, and the United States (Smith \& Abouammoh, 2013). The performance of such grant scheme was recognised by UNESCO, which ranked Saudi Arabia as the fourth nation in granting scholarship ahead of the US and Japan (Islam, 2014). Nowadays, current and next generations have a better chance of gaining university knowledge than the previous ones (Saifulhafizi, 2014).

If access to knowledge provision is rapidly improving, the performance of the universities as organisations is not. Several challenges are hindering the future success of these institutions. Indeed various research including (Alkhathlan et al., 2014; Hilal et al., 2015) have shown that the biggest challenge facing the Kingdom's major sectors is not policies, but the collapse of the oil industry whose wealth has been trickling down to all other sectors. To date, oil reserves are estimated to be depleted within 90 years. If universities continue to proceed the way they have been functioning, their very existence is at risk (Al-shehry, 2009). This comes at a time when the country is looking for ways to diversify its economy. As highlighted in the nation's Vision 2030 (Khan \& Khan, 2020), the KSA is expecting to boost the economy, create more job opportunities in the private sector, transfer state-owned assets to private organisations, and build on non-oil dependent exports. Education, notably HE, is considered an epicentre of the changes that are needed to take place in the nation shortly (Hilal et al., 2015). As stated by Hvidt (2013) in the Economic Diversification in Gulf Cooperation Council (GCC) countries publication, the government has recognised that post-secondary education has a crucial role to play in driving the nation socially and economically reduce the reliance on oil reservoirs. As such, a considerable amount of time and resources are being devoted to developing the R\&D sector, entrepreneurship initiatives, technology, and modern innovation. Such efforts are spearheaded not only to impart knowledge to students, but also to promote the expansion of off-campus high-value-added, knowledge economy businesses and jobs. In this vein, there has been an increasing trend in the number of interactions between businesses and Saudi universities. The relationship is promising, particularly considering that both universities and businesses are striving to better the national economy sustainably. However, this relation may be problematic as universities have traditionally considered themselves as learning institutions with three main goals: teaching, community service, and research (Hvidt, 2013).

The government has invested a lot in transforming Universities' facilities and services and adopting world-class standards. However, as was hinted by Al-shehry (2009), the transformation of the institutions is skewed toward traditional business practices; it is not very common to witness the adoption of pertinent learning organisations practices which will enable them to achieve the envisioned transformation. "Learning organisation" practices are described at the activities, programs and behaviours that enable organisations to develop new practises and acquire new knowledge to improve organisational performance and create a competitive advantage. For institutions trying to become "learning organisations", they still fail in executing some of the dimensions of learning organisation as was conceptualised by Yang, Watkins \& Marsick (2004). Learning organisations contracts are appropriate in the public education sector because they enhance knowledge acquisition. The ministry of education is looking forward to rolling our new curriculum that emphasises on enhancing critical thinking. Another important and perhaps very important for the present paper is the fact the ministry is also investing in training public universities' staff members. It also expected that the use of modern educational methods such as distance learning, multimedia and embedded learning, will be rolled out over the years to come (Al-shehry, 2009). In knowledge-driven economies, human capital is considered as one of the key drivers in the 
economy. Saudi Arabia has recognised this (Al-Musali \& Ku Ismail, 2014) and this is why the government is looking forward to creating a population composed of highly educated citizens (Othayman et al., 2020). In the coming years, the number of citizens holding degree and post degree programs will be high. This is good to the economy considering that specialised knowledge leads to better productivity. Education, particularly higher education is expected to have a rippling effect as per the predictions of the Saudi government Vision 2030 strategic framework.

\subsection{Significance of the Present Research}

In the present socio-economic context, the aims of the present research are twofold: First, it quantifies how Saudi Universities currently apply the main principles of a "learning organisation", and second, envisages how further development can be beneficial to universities, views that will be of interest to both the government and the private sector. Our findings will be useful to law and policy-makers as they are mandated to set out the general principles that govern the education sectors in a challenging and changing environment. The study will also prove useful to businesses that are looking for strategies to drive their firms into the future of the nation post the oil-reliant economy.

\section{Theoretical Review}

\subsection{Organizational Learning Theory}

Successful organisations are those that learn faster than their rivals and then employ the knowledge in their practices (Senge, 2014). The origins of organisational learning are traced back to the offset of the 1970s as cited by Argyris \& Schon (2011). The term organisational learning has been defined quite differently by past researchers, and this has created confusion around the subject (Goh, 1998). Therefore, there is no recognised unified definition of a "learning organisation" that has been cumulated by the previous researchers. The existing management literature has however been cited to skew towards the development of diagnostic tools useful to managers in identifying and enhancing their firm's learning capability.

Some researchers portray the "learning organisation" as a collective term that brings various concepts together (Mbuthia, 2018). Such definitions hold that a "learning organisation" refers to is the sum of individual learning in an organisation and organisation learns in only two ways: (a) by the learning of its members or (b) by ingesting new members who know the organisation did not previously have (Senge, 2014). However, these definitions all tend to consider the organisation as if it was an organism with a nervous system that would commit errors because of biased cognitive systems and memories, that conserve specific values, norms, and organisational behaviors. These organisational memories would, in turn, influence the employees and team learning in the organisation (Senge, 2014).

Previously there have been several attempts to design versions of the organisational learning (OL) models. They include what has been termed as a classical model, a multifaceted model, a computational model, or a sociological model (Senge, 2014; Mbuthia, 2018). In the OL framework, much of the evidence indicates that the key differentiator between public and private sectors mainly reside in one dimension describing how individual member of the organisation integrate new knowledge. Employee learning in organisations in the public sector has particularly been found to be the following models that are different from those in the private sector. This difference is mostly because these organisations are influenced by drivers that emanate from the political arenas. There has been a major shift as different campaigns urge for the adoption of reforms that enhance the capacity of the public organisations to meet demands for the citizens and changes in technology.

This has evoked the issue of employee learning in public institutions and the link to innovation and organisational change. A study conducted by (Goh, 1998) showed that the institutions in the public sector had higher levels of learning as compared to private institutions.

The Learning organisation as a construct has borrowed notions and concepts from various disciplines, including organisational development, cognitive science, and system theory. There is a clear line of separation between organisational learning and learning organisation. While organisational learning is a by-product of normal work, a "learning organisation" is a process that creates constant learning. A learning organisation can be used as a tool to achieve the various aspects of organisational performance such as shareholder returns, financial performance, and product market (Argyris \& Schon, 2011).

Senge (2014), states that learning organisation is institutions of creativity and innovation via the creation of free and enabling environments. A "learning organisation" forms a good environment that enables people to expand their capacity to achieve desired goals continuously. In such an organisation, thinking out of the norms, collective goals are encouraged. This is the kind of organisation that Yang, Watkins \& Marsick (2004) describe as possessing capabilities to constantly adapt and update itself in a changing business market. In 1990, Senge identified five salient so-called disciplines (or required set of competencies) in the learning organisation. These disciplines include the need to adopt system thinking/connection, a reliance on personal mastery (the 
commitment of employees to the organisation's learning), mental models, the adoption of a shared vision, and the ability for a team to learn. He later updated these disciplines in his 1994 papers where he codified the practices that organisations should use to become 'learning organisations' (Senge, 1994). Senge called these practices The 5 Learning Disciplines. The paper also explained why some organisations become better at building learning capacity than others. The five learning disciplines are important to this research because each of them is composed of a set of practices and tools which are inclined to create a sustainable leadership capacity. Senge described leaders as individuals put in a position to thrive on constant innovation and change by utilising the five disciplines. Whether in nonprofit organisations like public universities or profit-oriented businesses, the approach to learning-centered leadership and improvement is grounded on language, principles, concepts, and values of learning organisations (Senge, 1994; 2014).

\subsection{The Various Disciplines of a "Learning Organisation"}

\subsubsection{System Thinking}

System thinking is considered to be the cornerstone among the other five disciplines. It refers to the ability to envision the big picture, the ability to not only understand the whole picture but also the components that create the motive and means to integrate other disciplines. Businesses encounter different challenges some of which are simple, while others are complex to handle. To succeed organisation are required to focus and familiarise themselves with the complexities at hand. One of the best ways to handle a complicated situation is the application of simple strategies. According to Senge (2014), simple strategies offer a quick solution and high chances of leading to organisational performance. However, these strategies also present the risk of compromising the future of the organisation. Organisational leaders tend to look at organisations as a part of a bigger picture instead of looking at the organisation's full picture. Senge (1990) shared the phrase that organisations learn best through experience. Certain short-term actions or simple strategies to reduce advertising as a way to cut on the operational cost may lead to a drop in the long-term sales of the organisation. This reiterates the argument made earlier that simple strategies maybe solutions to complex situations, but they cause an adverse impact in the future. The organisational leaders, therefore, need to be acquainted with enough knowledge and experience to perform such steer the organisation in the right direction.

System thinking also states that changing or disrupting the flow of power in an organisation causes ripple effects on the action and decisions made. The managers also need to keep abreast of the feedback system established in the organisation. Ignoring the feedback from the users of organisations may lead to short term as well as the long-term impact of the performance of the organisation.

\subsubsection{Personal Mastery}

Personal mastery is another "discipline" that is concerned with the employees' commitment to the firms' learning (Barker \& Camarata, 1998). It is also concerned with the so-called "real spirit" that exists in an organisation. The discipline of personal mastery emphasises the need for an employee to pursue personal improvements. Individuals should choose those activities or accusations that bring out thrill and utilise the utmost potential. But to work at full potential, a person should recognise his or her weakness and strengths.

The discipline of personal mastery also urges individuals, who in this case may be managers and other organisational employees to train their minds to handle complex situations through exposure. Activities aiming at developing this aspect of problem-solving should be encouraged to eliminate repeating mistakes by instilling in employees that they can tackle the challenges they may be facing. According to (Hamann et al., 2013) the best way that an organisation can nature personal mastery is by allocating employees the tasks that are in line with their best capabilities.

\subsubsection{Mental Models}

The mental models are also important for a learning organisation since they enable an organisation to grow and have a vision of what they want to achieve. Mental models caused educational conversations in the firms which help in the idea and opinion sharing (Dervitsiotis, 1998).

\subsubsection{Shared Vision}

Also, building a shared vision is another dimension of a learning organisation that enables the creation and development of goals, objectives, and vision through positive interactions (Senge, 2014). The primary participants of the interactions are the organisational employees. A shared vision should be developed early so that a common understanding is created through conversations. Shared vision means that the members should identify what they want to create together. Tools needed by leaders include values alignment, concept shifting, and positive visioning. Building a shared vision creates organisational performance through unity in the working of the whole firm in one direction (Senge, 2004).

\subsubsection{Team Learning}


In addition to building a shared vision, there is also a need to develop on another dimension, namely; team learning. Team learning brings together "personal mastery" and "shared vision". Team learning in an organisation prevents employees to shun from internal rivalry. Employees hence work as a team and are free to share ideas with others freely. According to (Fillion, Koffi \& Ekionea, 2015) such an organisation creates an environment that leads to open dialogues and forgiveness. Team learning, therefore, happens in an organisation when teams start thinking in similar ways by sharing skills, knowledge, insights, and experience as a way to do things better (Senge, 2014).

\subsection{Empirical Review}

It is believed that organisational learning creates the best conditions where employees can continually expand their capacity to perform, nurture new thinking patterns and set their aspirations free in the quest to reach a bigger vision (Senge, 1990; 2014). The five disciplines conceptualised by Senge provide a very useful framework in which to understand the inner workings of the organisation, and how it approaches learning-centered leadership and how improvement is based on language, principles, concepts, and values of learning organisations (Senge, 2014). However, for an organisation to become a learning organisation, many other criteria are required to be fulfilled.

As Public universities strive to become effective learning organisations, they need to develop along seven dimensions as it is argued in Marsick and Watkins (2003). The present research will look at the dimensions of learning organisation namely; continuous learning, inquiry and dialogue, team learning and collaboration, embedded system, Empowerment, system connection, and strategic leadership.

\subsubsection{Dimensions of the Learning Organization}

\subsubsection{Continuous Learning}

Continuous learning in an organisation strives to create constant learning opportunities for all members from the top management team to the employees (Hung et al., 2010). It is also enhancing the capabilities of the employees to meet the set objectives. The dimension also benefits the individual employee because they become better placed in the competitive job market. According to Hung et al. (2010), continuous learning is a good opportunity for individuals to acquire a better skill set. It also aids in the retention of employees because of the process of learning and developing them within offers the organisation the skills needed without recruiting new employees. It has been argued that continuous learning creates the advantage of creating more productivity due to effectiveness, innovations, and competitiveness aspects. In the modern world, there is a need for an organisation to remain in business and show constant growth; this demand can only be met by continuous learning. A 2016 study conducted by Ponnuswamy\& Manohar revealed that the organisational performance of public universities was highly correlated to culture of organisational learning. There are several ways of creating learning opportunities in an organisation; this includes the development of: research grants; training programs, and scholarships to academics (Ponnuswamy\& Manohar, 2016; Othayman et al., 2020).

\subsubsection{Inquiry and Dialogue}

Inquiry and dialogue entail the knowledge acquiring by individuals from others. Employees in an organisation with this dimension are good listeners and take the views of others with intent (Hussein et al., 2014). It is important to cultivate the spirit of inquiry as a way of enhancing the ability to understand basic beliefs and assumptions. A setting that is informal, and without distractions, creates opportunities for people to identify commonalities between themselves.

Hamann et al. (2013) found that there is a positive effect of learning in an organisation on organisational performance. The research revealed that inquiry and dialogue were two significant factors in that they cause efficient communication and system thinking and the organisation is more likely to encourage open communications. In such a firm, communication is a two-way process which creates ground for opinion and idea sharing as well as innovation. In a different but related research (Laeeque \& Babar, 2015), studied in hospitals which used certain dimensions of the learning organisation. Results showed that inquiry and dialogue enabled the staff to take more risks, experiment new things, and enquire more freely. The staff team was also intended to feedback from patients and respond appropriately. When this is combined with continuous learning, it leads employees that not only are eager to learn but are willing to explore, question the status quo, and come up with innovative ideas. Organisations are frequently faced with various challenges that put the managers in complex situations that need dialogue. To establish a common understanding in such circumstances, robust inquiry and dialogue is the best action for the business (Hamann et al., 2013).

\subsubsection{Team Learning and Collaboration}

A so-called "intelligence of a team" that is well structured surpasses that of an individual several folds (Hamann, et al., 2013) as can be seen in areas such as sports, science, and arts. This is also true for organisations where 
staff members work as a team. As a dimension of a learning organisation, team learning is concerned with the practice of team members coming up with ideas and skills as well as a way to share them with others. When team learning is combined with collaboration, the members see and treat each other as colleagues. As such, the employees at the bottom of the organisational hierarchy should feel free to share ideas and opinions with those at the executive level.

Working together as a team enhances the chances and capability of achieving the organisational objectives. Organisations should preserve the knowledge created during teamwork and collaboration. Although the team members may be at different levels of learning, support, and trust in each other leads to better team performance (Yang et al., 2004). According to Marsick and Watkins (2003) the conditions in an organisation influence team learning and dictates whether team learning becomes organisational learning.

\subsubsection{Embedded System}

This notion stresses the importance of capturing knowledge learned, maintaining, and sharing it through all levels of management in the organisation (Yang et al., 2004). Organisations usually come up with means of storing the learned skill and practices because they help them manoeuvre during time of turbulence in the market and high employee turnover. A system of sharing captures knowledge is needed when needs arise to generate and maintain data to make an organisation better. A learning organisation has a culture of putting together an account of information that can easily be accessed and retrieved when needed. The retrieved information can then be disbursed and spread within the organisation, especially to the new members joining the organisation (Marsick \& Watkin, 2003).

An embedded system should utilise low technology systems which makes it efficient for analysis through focused group discussions. The organisation with an embedded system comes up with systems of measuring the gaps between the current and expected results. Also, time and resources spent during the learning lessons of employees are measured. Such an embedded system is paramount in the continuity of a learning culture and performance in the organisation (Sharifirad, 2011).

\subsubsection{Employee Empowerment}

The Empowerment of the staff is another dimension of learning organisation which focuses on making employee yearn to attain the shared or collective organisational vision. This discipline's success is however dependent on the use of collaborative practices. Employee empowerment is described by some researchers as a course by which the rights and the will of individuals are increased through cooperation, training, sharing, and help. But according to Field (1997), the term employee empowerment has undergone several reviews and changes in line with the change and competition in the global job market. Employee engagement can be broken down into four aspects; (1) the performance of the enterprise, (2) the power to make decisions, (3) the information on performance, and (4) the actual enablement of an understanding of performance and contributions (Fernandez \& Moldogaziev, 2013). Marsick and Watkin (2003) put forward the argument that having control of one's motivation, cognition and personality is Empowerment. It is seen in the lines of capacity to effect changes and self-worth. Employee empowerment, especially towards a common vision, leads to commitment in the organisation (Watkin \& Marsick, 2003).

\subsubsection{System Connection}

System connection is the sixth dimension among the dimensions of learning organisation as drafted by Marsick and Watkin (2003). According to Senge (1990), organisations usually suffers from inertia and realises how hard it is to keep pace with a changing environment. As stated by Carter and Greer (2013) the more time an organisation takes to flow with the market changes, the fewer the option is for it to regain back its desired position. Having an effective system connection would help the organisation to capture and enhance organisation capability to be successful.

Oh (2019) stated that a system connection also had a mediating and positive impact on the relationship between Empowerment, continuous learning and organisational performance. An effective system connection also is considered as a base to clarify the bigger picture of the organisation (Sayed \& Edgar, 2019). This includes giving employees support, time, identification of skills for future tasks and open discussions to identify mistakes and reward for learning.

\subsubsection{Strategic Leadership}

Strategic leadership increase the share of decision-making from the top of the hierarchy to lower ranks. The effect is that everyone sees the need to connect to those on top or lower levels of management and in the process form relationship that are both authentic and lasting (Marsic \&Watkin, 2003).

The principles of strategic leadership should help an organisation to shift capabilities and resources to create a strategic advantage to the organisation against external completion and changing markets. Existing research 
indicate that strategic leadership can change the culture of an organisation, its structure, and system of reward to foster performance. Strategic leadership is also associated with enhancing the creation of systems for capturing information and boost learning in an organisation. It allows for the spread of information within an institution as well as the creation of new knowledge (Marsic \&Watkin, 2003; Sharifirad 2011).

\subsection{Measuring Organisational Performance in HE Organisations}

Measuring performance is a process that entails the collection, analysing and reporting data of a component, group or organisation (Marlow et al., 2018). Measuring organisational performance not only in universities as well as other organisations creates a challenge because it is multidimensional theoretical construct in nature. As such, there is no single operational measure that a researcher can use as a definite solution. The multi-dimensional aspect of the variable means that, its unclear whether the results should be portrayed for unitary or as multiple purpose, which affects reliability. However, researchers (Goyal, 2013; Phusavat et al., 2011) agreed that the best measures of measuring organisational performance should be in terms of financial measures such as return on assets, return on equity, return on asset etc. Also, organisational performance can also involve qualitative measures which include research, competitiveness, resource generation, knowledge creation, teaching and learning (Soon \& Zainol, 2011). According Salau et al. (2016), several other duties and activities are expected from universities such as mentoring, community service, teaching, routine administration and assessment.

Another important aspect that is fundamental in universities organisational performance is research. Research is defined as the systematic study and investigation of sources and material with the goals of establishing facts and making conclusions. According to Shepherd \& Gruber (2020), research is a process of generating new insights and knowledge or unlocking new knowledge. In the field of academics, research is regarded as a key performance indicator. Although students face many emerging challenges, it is recommended that the management and authorities support universities in conducting and publishing research projects. Research goes hand in hand with teaching and as (Onwuegbuzie et al., 2007), points out, it is the sharing of knowledge and skills by persons in authority, teachers, in a form that is understandable and relevant to students. The teacher needs to acquire skills which are expressed as micro behaviors that make teaching effective. Community service is expressed as the system for giving support to nurture and sustain the lives of families, groups and individuals to realise their potential for the well-being and development of the society. There are many activities that an organisation can undertake to improve the lives of the people around them (Karakas, 2010). As mentioned earlier the researcher chose to explore the university performance using the qualitative measures including knowledge creation and research.

\subsection{Conceptual Framework}

The conceptual framework of the present paper emphasises the relationship that exists between dependent (performance measures) and independent variables. Organisational performance of the selected public universities forms the depended variables while independent variables entail the dimensions of a learning organisation; continuous learning, inquiry and dialogue, team learning and collaboration, embedded system, Empowerment, system connection and strategic leadership based on the impact dimensions of learning organisations developed by Marsick and Watkin (2003). 


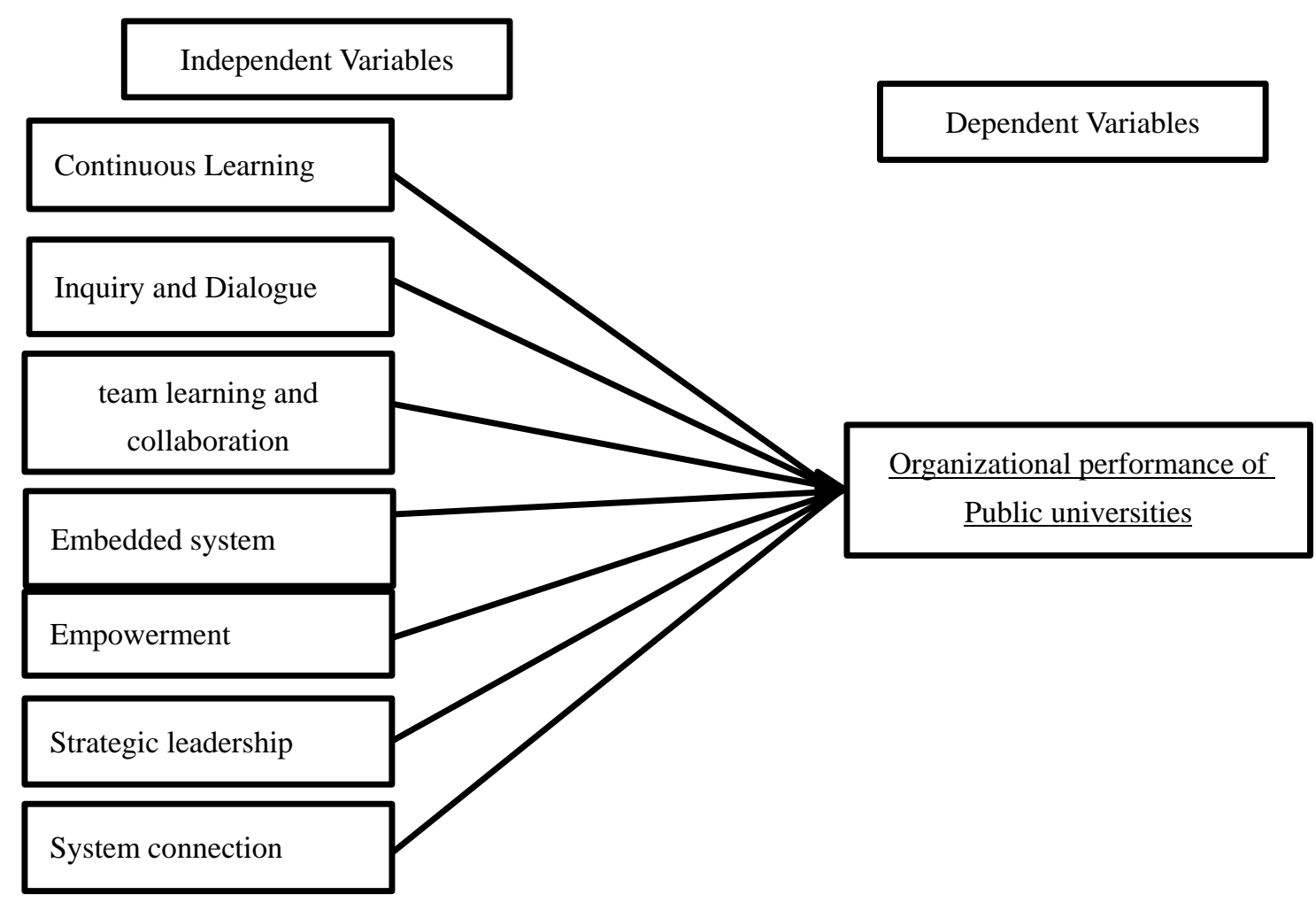

Figure 1. The conceptual framework

The aim of this paper is to address the direction of higher education institution in Saudi Arabia becoming a learning organisation through assessing the application of dimensions of learning organisation in public universities, assessing dimensions of learning organisation which are associated with organisation performance in the institutions under study and to assess the extent to which the application of learning organisation is affected by demographic variables.

\subsection{Research Questions}

In line with the objectives, the study sought to answer the following questions

i. To what extent are the dimensions of learning organisation used in public universities in KSA?

ii. What are the dimensions of a learning organisation that affect organisational performance in universities?

iii. To what extent is the application of learning organisation affected by demographic variables?

\section{Research Methodology}

According to Fleiss, Levin, and Paik (2013), a sample is the demonstrative section of the whole population whereas how that section is single out is called the sampling technique. To minimise sampling error and come up with a suitable representative, the paper employed a stratified random sampling technique. The technique involves two processes where the target population is divided into strata and then elements are picked from each of the strata by simple random sampling. We used a close-ended questionnaire. The questionnaire which was adopted from Watkins \& Marsick (2003) contained 28 questions which had cover the different variables of the study. All the answers provided by the participants were measured on a similar Likert scale ranging from 1 to 6 . The corresponding answer for the seven-learning dimensions translate to "Strongly disagree" up to "Strongly agree", whereas for the organisation performance translate to "Almost never" up to "Almost always". Questionnaires were sent through emails to the target population. The researchers distributed 976 questionnaires of which 840 were returned (response rate of $86 \%$ ). For each group of questions, the average of the answers was computed for further analysis. The average is assumed to have captured the information of each learning dimension of the organisation performance.

\subsection{Research Reliability and validity}

A Cronbach alpha score test on Likert scale was used to check the reliability (or internal consistency) of this 
research. It resulted in an overall Cronbach alpha of 0.972; a value deemed acceptable Bland \& Althman, 1997. To ensure the validity of the research tools, this study ensured the creation of objective questions for the questionnaire. We were careful in covering all the variables (OP, demographics) as well as using related questions. We pretested our questionnaire in a pilot study where ten questionnaires were sent to experts in the field and some potential participant of the targeted sample to ensure that all variables and related questions were included. Later, errors and omissions were corrected to ensure that the questionnaire was valid. We also explored the construct validity was used to determine the link of the instrument to the theoretical assumptions and concepts (Kim, Egan, \& Tolson, 2015)

Table 1. Cronbach alpha values for the overall questionnaire and each variables

\begin{tabular}{|l|l|l|l|l|l|l|l|l|}
\hline $\begin{array}{l}\text { Overall } \\
\text { questionnaire }\end{array}$ & $\begin{array}{l}\text { Continuous } \\
\text { learning }\end{array}$ & $\begin{array}{l}\text { Inquiry } \\
\text { and } \\
\text { Dialogue }\end{array}$ & $\begin{array}{l}\text { Team } \\
\text { learning and } \\
\text { collaboration }\end{array}$ & $\begin{array}{l}\text { Embedded } \\
\text { system }\end{array}$ & Empowerment & $\begin{array}{l}\text { System } \\
\text { connection }\end{array}$ & $\begin{array}{l}\text { Strategic } \\
\text { leadership }\end{array}$ & $\begin{array}{l}\text { Organisational } \\
\text { performance }\end{array}$ \\
\hline 0.972 & 0.777 & 0.730 & 0.871 & 0.925 & 0.911 & 0.872 & 0.910 & 0.936 \\
\hline
\end{tabular}

\subsection{Data Analysis}

The data collected for this paper were analysed using STATA. We used multiple regression analyses to establish the relationship between how the dimensions of learning organisation affect the organisational performance. We also used multi-way ANOVA to characterise how demographic variables affected learning dimensions and organisational performance (Babbie et al., 2018).

\section{Results}

\subsection{Descriptive Statistics}

The present research sampled 840 employees (533 males and 307 females) from 20 universities across all regions of Saudi Arabia. Figure 2 presents the percentage allocation of the respondents in the universities. The sample size was large enough to provide confidence as for the conclusions drawn and the geographical spread of the respondents provides strong evidence to expand the conclusions at a Saudi national level. Table 2 shows the descriptive statistics of the research sample.

Table 2. Descriptive statistics for the categorical variables

\begin{tabular}{|c|c|c|c|c|c|c|c|c|c|}
\hline $\begin{array}{c}\text { Gend } \\
\text { er }\end{array}$ & $\begin{array}{c}\text { Frequenci } \\
\text { es } \\
(\%)\end{array}$ & Age & $\begin{array}{c}\text { Frequenci } \\
\text { es }(\%)\end{array}$ & $\begin{array}{c}\text { Educati } \\
\text { on }\end{array}$ & Frequencies (\%) & $\begin{array}{c}\text { Work } \\
\text { experien } \\
\text { ce }\end{array}$ & $\begin{array}{c}\text { Frequenci } \\
\text { es (\%) }\end{array}$ & $\begin{array}{c}\text { Administrat } \\
\text { or position }\end{array}$ & $\begin{array}{c}\text { Frequenci } \\
\text { es (\%) }\end{array}$ \\
\hline Male & $\begin{array}{c}533 \\
(53.5)\end{array}$ & $\begin{array}{c}21-3 \\
0\end{array}$ & $\begin{array}{c}222 \\
(26.4)\end{array}$ & $\begin{array}{c}\text { Bachelo } \\
\text { rdegree }\end{array}$ & $301(35.8)$ & $>1$ years & $55(6.5)$ & Dean & $42(5.0)$ \\
\hline $\begin{array}{c}\text { Femal } \\
\text { e }\end{array}$ & $\begin{array}{c}307 \\
(36.5)\end{array}$ & $\begin{array}{c}31-4 \\
0\end{array}$ & $\begin{array}{c}335 \\
(39.9)\end{array}$ & $\begin{array}{c}\text { Master } \\
\text { degree }\end{array}$ & $240(28.5)$ & $\begin{array}{c}1-3 \\
\text { years }\end{array}$ & $\begin{array}{c}106 \\
(12.6)\end{array}$ & Vice Dean & $45(5.4)$ \\
\hline & & $\begin{array}{c}41-5 \\
0\end{array}$ & $\begin{array}{c}223 \\
(26.5)\end{array}$ & $\mathrm{PhD}$ & $254(30.2)$ & $\begin{array}{c}3-5 \\
\text { years }\end{array}$ & $97(11.5)$ & $\begin{array}{c}\text { Department } \\
\text { chairman }\end{array}$ & $40(4.8)$ \\
\hline & & $\begin{array}{c}51-6 \\
0\end{array}$ & $55(6.5)$ & other & $45 \quad(5.4)$ & $>5$ years & $\begin{array}{c}225 \\
(26.8)\end{array}$ & $\begin{array}{c}\text { Centre } \\
\text { director }\end{array}$ & $33(3.9)$ \\
\hline & $\geq 61$ & $5(0.6)$ & & & $\begin{array}{c}>10 \\
\text { years }\end{array}$ & $\begin{array}{c}357 \\
(42.5)\end{array}$ & $\begin{array}{c}\text { Administrat } \\
\text { or manager }\end{array}$ & $88(10.5)$ \\
\hline & & & & & & $\begin{array}{c}\text { Academic } \\
\text { staff }\end{array}$ & $\begin{array}{c}380 \\
(45.2)\end{array}$ \\
\hline & & & & & & $\begin{array}{c}\text { Non-acade } \\
\text { mic staff }\end{array}$ & $\begin{array}{c}212 \\
(25.2)\end{array}$ \\
\hline
\end{tabular}




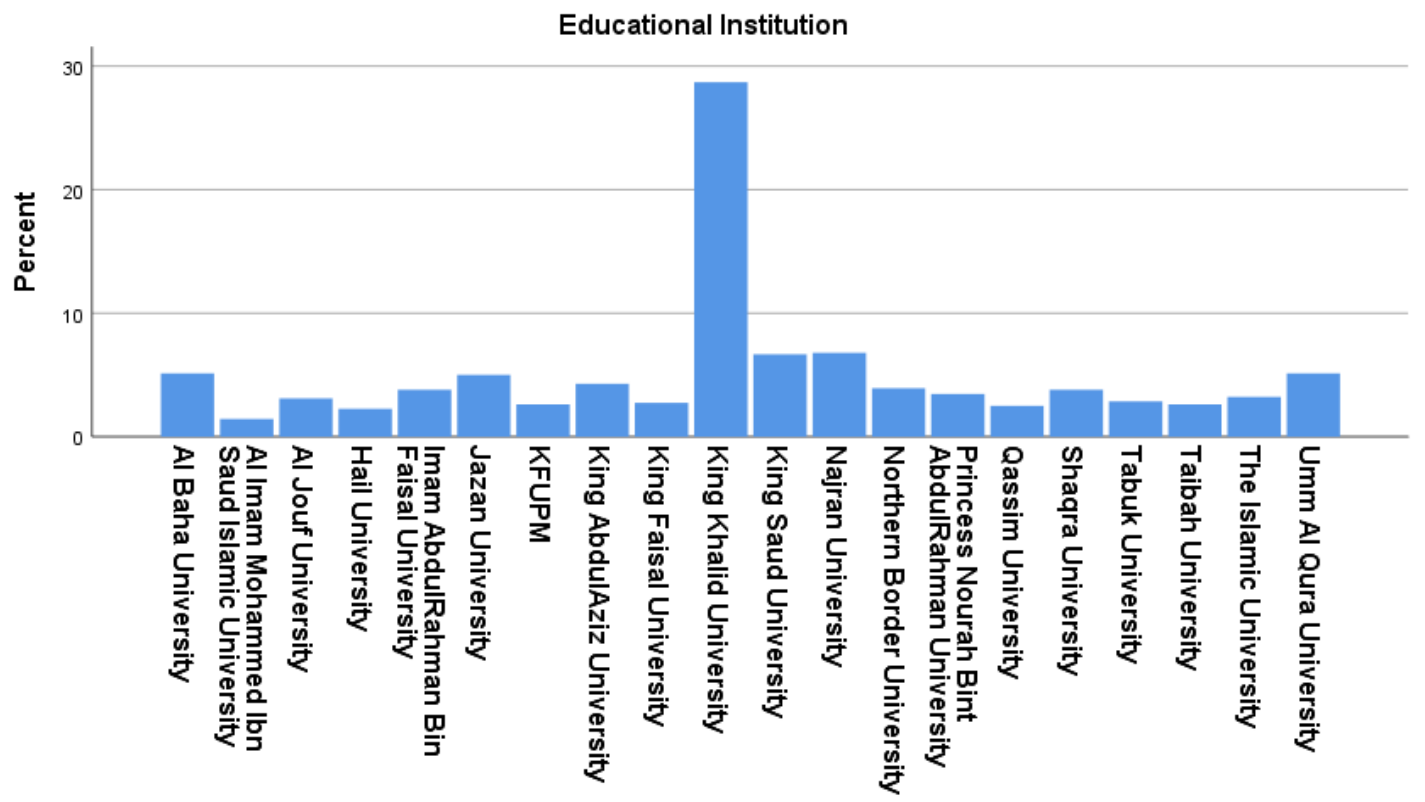

Figure 2. Allocation of employees in the universities under investigation (in \%)

\subsection{Inferential Statistics}

Research question (i) To what degree are Saudi Arabia's public universities adopting the various dimensions of an ideal "learning organisation"?

The average and its associated upper- and lower-bound 95\% confidence interval are presented in Table 2 and Figure 2 visualises the confidence intervals. All averages were below 4 and no confidence intervals ever include 4. If the minimum level was set to 4, then clearly all learning dimensions and the organisation performance tend not to be learning originations. Regardless of the interpretation of value 4, the conclusion is that there is room for improvement. The Empowerment and Embedded system have the lowest score values, and their averages and confidence intervals are similar. Overall, the average values were not high, indicating that work needs to be done to effectively improve these numbers.

Table 2. Means And 95\% Confidence Intervals of the Learning Dimension and Of The organisation performance

\begin{tabular}{|c|c|c|c|c|}
\hline & \multirow[t]{2}{*}{ Mean } & \multicolumn{2}{|c|}{ 95\% Confidence Interval } & \multirow{2}{*}{$\begin{array}{l}\text { Degree of adaptation of the } \\
\text { learning dimensions }\end{array}$} \\
\hline & & Lower & Upper & \\
\hline Continuous learning & 3.64 & 3.54 & 3.72 & 0.60 \\
\hline Inquiry and dialogue & 3.88 & 3.79 & 3.95 & 0.64 \\
\hline $\begin{array}{l}\text { Team learning and } \\
\text { collaboration }\end{array}$ & 3.71 & 3.62 & 3.79 & 0.62 \\
\hline Embedded system & 3.57 & 3.47 & 3.66 & 0.59 \\
\hline Empowerment & 3.59 & 3.49 & 3.68 & 0.59 \\
\hline System connection & 3.78 & 3.66 & 3.85 & 0.63 \\
\hline Strategic leadership & 3.75 & 3.66 & 3.85 & 0.62 \\
\hline
\end{tabular}




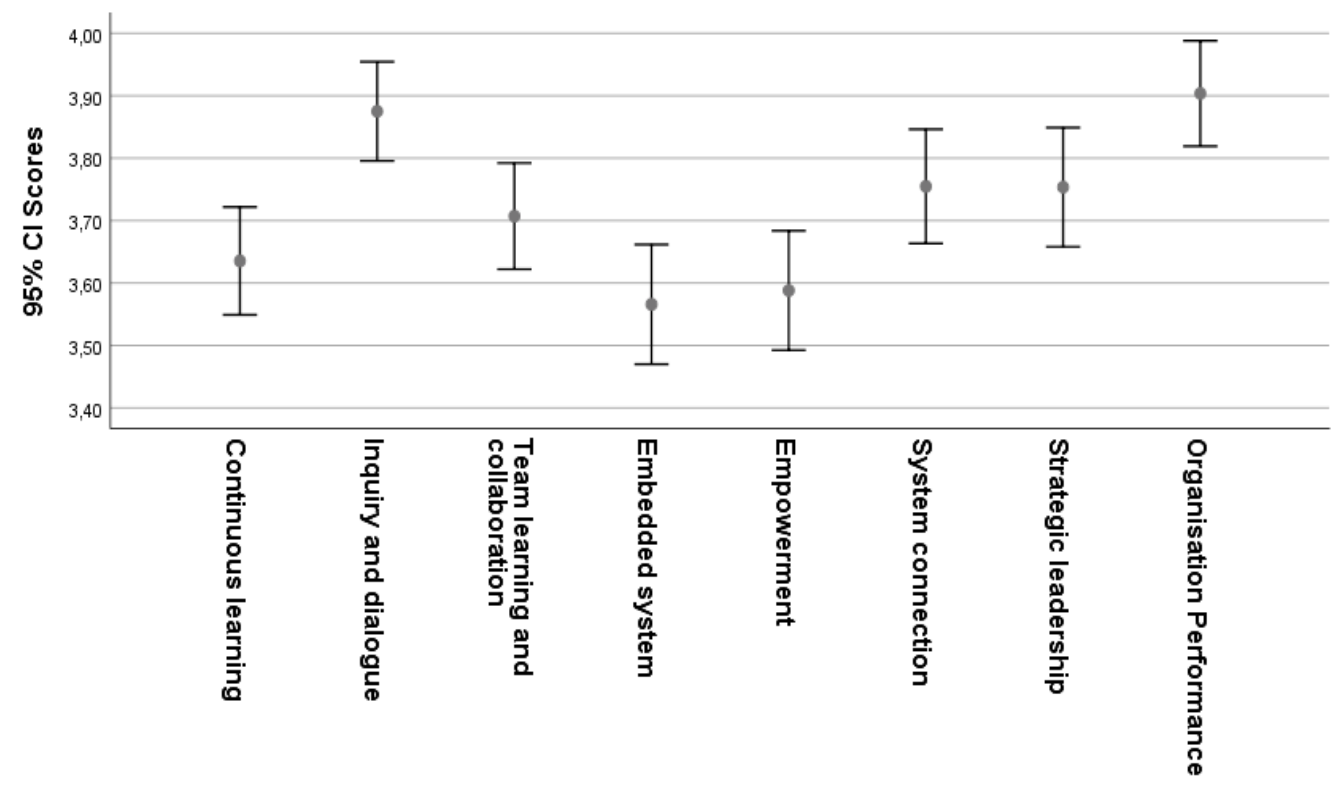

Figure 3. Mean scores for the seven learning dimension and the organisation performance (error bars represent the 95 th confidence intervals)

Research question (ii) What dimensions of learning organisation are associated with organisation performance in the institutions under study?

Pearson's correlations and linear regressions were employed to answer the second question. The correlation of the organisation performance with each of the seven "learning dimensions has been tested. All correlations between the organisation performance and the dimensions of learning organisation were strong (all .757> $r \mathrm{~s}>.531$ ) and statistically significant (all $p \mathrm{~s}<.001$ ), meaning that there is a linear relationship between the organisation performance and each dimension. A second step was to identify the effect of each learning dimension on the organisation performance when the former was collectively examined. A backward selection method was at first applied to identify the learning dimensions that are statistically significantly related with the organisational performance and a regression model was fitted.

The backward selection method estimated that the embedded system learning dimension did not contribute significantly to the modelling of the organisation performance and excluded this dimension. The linear regression of organisation performance on the six other learning dimensions is presented in Table 3 . All $p$ s of the regression coefficients were statistically significant at the $5 \%$ level. The B coefficient of the continuous learning (0.149) was higher than the coefficient of the Team learning and collaboration (0.160). Yet, the former was statistically more significant than the latter. The t-statistic of the Continuous learning was 4.432, while the t-statistic of the Team Learning and Collaboration was 4.255. On the other hand, the Strategic Leadership had the highest effect on organisation performance and was also the most important learning dimension. This learning dimension was found to be the most correlated with the organisation performance.

We computed a Variance Inflation Factor (VIF) to measure the strength of the inter-relationships between learning dimensions. Values higher than 10, would indicate a problematic linear regression model and the relevant learning dimensions would have to be removed. In this case, the highest VIF value was less than 5, hence all learning dimensions seem to conform with this condition.

All learning dimensions have a positive effect on the organisation performance, except for the Inquiry and dialogue. However, this variable was not as statistically significant as the other ones and could be eliminated from the model without significant losses. The $\mathrm{R}^{2}$ of the regression model is 0.653 . This means, that $65.3 \%$ of the total variation of the organisation performance is explained by the model indicating that the fit of the model is satisfactory.

We fitted the actual values against the residuals to explore possible violation of the assumption of residuals homoscedasticity and found none.

Table 3. Linear regression of organisation performance on six learning dimensions (backward selection method) 


\begin{tabular}{|c|c|c|c|c|c|}
\hline (Constant) & 0.898 & 0.093 & 9.705 & 0.000 & \\
\hline Continuous learning & 0.149 & 0.034 & 4.432 & 0.000 & 2.822 \\
\hline Inquiry and dialogue & -0.070 & 0.033 & -2.103 & 0.036 & 2.361 \\
\hline Team learning and collab. & 0.160 & 0.037 & 4.255 & 0.000 & 3.416 \\
\hline Empowerment & 0.136 & 0.035 & 3.838 & 0.000 & 3.867 \\
\hline System connection & 0.143 & 0.041 & 3.532 & 0.000 & 4.645 \\
\hline Strategic leadership & 0.298 & 0.035 & 8.536 & 0.000 & 3.739 \\
\hline
\end{tabular}

Research question (iii) To what extent the application of "learning organisation" is affected by demographic variables?

The last research question seeks to identify the effect of the demographic variables on the learning dimensions and the organisation performance. A Multi-way ANOVA was carried out.

Continuous learning:

Education level and work experience were the two key factors statistically significantly associated with Continuous learning (respectively $\mathrm{F}(3,839)=5.350, \mathrm{p}<0.001 ; \mathrm{F}(4,839)=3.067, \mathrm{p}<0.016$ ). However, Age, Gender and Administrative position were not significantly associated (all $\mathrm{F}<1.9$, all ps $=\mathrm{NS}$ ). The Levene's test for homoscedasticity was not significant.

Inquiry and Dialogue:

The education level $(\mathrm{F}(3,839)=5.195, \mathrm{p}=0.001)$, the work experience $(\mathrm{F}(4,839)=3.335, \mathrm{p}=0.01)$ and the administrator position $(\mathrm{F}(6,839)=3.204, \mathrm{p}=0.004)$ were the three key factors statistically significantly associated with the Inquiry and dialogue. The Levene's test for homoscedasticity was not significant.

Team learning and collaboration:

The education level $(\mathrm{F}(3,839)=7.112, \mathrm{p}<0.001)$ and the administrator position $(\mathrm{F}(6,839)=2.136, \mathrm{p}=0.047)$ were the two key factors statistically significantly associated with the Team learning and collaboration. The Levene's test was rejected $(\mathrm{F}(235,604)=1.233, \mathrm{p}=0.024)$ suggesting heteroscedasticity in the residuals and results should be treated with caution.

Embedded system:

The education level $(\mathrm{F}(3,839)=9.284, \mathrm{p}<0.001)$ and the administrator position $(\mathrm{F}(6,839)=2.567, \mathrm{p}=0.018)$ were the two key factors statistically significantly associated with the Embedded system. The Levene's test for homoscedasticity was not significant.

Empowerment:

The education level $(\mathrm{F}(3,839)=5.202, \mathrm{p}=0.001)$ and the administrator position $(\mathrm{F}(6,839)=6.375, \mathrm{p}=0.006)$ were the two key factors statistically significantly associated with the Empowerment. The Levene's test for homoscedasticity was not significant.

System connection:

The education level $(\mathrm{F}(3,839)=3.975, \mathrm{p}=0.008)$ and the administrator position $(\mathrm{F}(6,839)=3.144, \mathrm{p}=0.005)$ were the two key factors statistically significantly associated with the System connection. The Levene's test for homoscedasticity was not significant.

Strategic leadership:

The education level $(\mathrm{F}(3,839)=7.923, \mathrm{p}<0.001)$ and the administrator position $(\mathrm{F}(6,839)=2.455, \mathrm{p}=0.023)$ were the two key factors statistically significantly associated with the Strategic leadership. The Levene's test for homoscedasticity was not significant.

Organisation performance:

The only statistically significant demographic variable was the education level $(\mathrm{F}(3,839)=3.157, p=0.024)$. Practically this means, that neither gender, age, work experience, or the administrator position differentiates the organisation performance of the employees. It is their education level that shows differences in the organisation performance. The education level was then further investigated and revealed that the organisation performance of the employees with $\mathrm{PhD}$ was statistically higher than the organisation performance of the employees with Master's degree. The only statistically significant difference in the organisation performance was detected between the $\mathrm{PhD}$ and Master holders. PhD holders had an average organisation performance of 0.335 higher than the average organisation performance of the Master holders.

The Levene's test for homoscedasticity was not significant $(\mathrm{F}(235,604)<0.05)$.

Table 4 summarises the important demographic factors for each learning dimension and organisation 
performance. Education level is always present, administrator position is important for most cases, whereas work experience was significant only two times.

Table 4. Demographic variables statistically associated with each learning dimensions and organisation performance

\begin{tabular}{|c|c|c|c|}
\hline & Education level & Work experience & Administrator position \\
\hline Continuous learning & $\mathrm{F}(3,839)=5.350, p<0.001$ & $\mathrm{~F}(4,839)=3.067, p<0.016$ & NS \\
\hline Inquiry and dialogue & $\mathrm{F}(3,839)=5.195, p=0.001$ & $\mathrm{~F}(4,839)=3.335, p=0.01$ & $\mathrm{~F}(6,839)=3.204, p=0.004$ \\
\hline $\begin{array}{l}\text { Team learning and } \\
\text { collaboration }\end{array}$ & $\mathrm{F}(3,839)=7.112, p<0.001$ & NS & $\mathrm{F}(6,839)=2.136, p=0.047$ \\
\hline Embedded system & $\mathrm{F}(3,839)=9.284, p<0.001$ & NS & $\mathrm{F}(6,839)=2.567, p=0.018$ \\
\hline Empowerment & $\mathrm{F}(3,839)=5.202, p=0.001$ & NS & $\mathrm{F}(6,839)=6.375, p=0.006$ \\
\hline System connection & $\mathrm{F}(3,839)=3.975, p=0.008$ & NS & $\mathrm{F}(6,839)=3.144, p=0.005$ \\
\hline Strategic leadership & $\mathrm{F}(3,839)=7.923, p<0.001$ & NS & $\mathrm{F}(6,839)=2.455, p=0.023$ \\
\hline $\begin{array}{l}\text { Organisation } \\
\text { performance }\end{array}$ & $\mathrm{F}(3,839)=3.157, p=0.024$ & NS & NS \\
\hline
\end{tabular}

\section{Discussion}

The present results emphasize that the learning dimensions of the learning organisation framework are not utilised, at sufficient levels, in public universities in Saudi Arabia. The relationships between most learning organisations and the organisation performance are highly positive and highly statistically significant. Finally, the education level seems to be the only demographic factor that affects all learning dimensions and the organisation performance. The administrator position is a key demographic factor for most learning dimension, but work experience seems to affect significantly only two learning dimensions.

\section{To what degree are Saudi Arabia's public universities adopting the various dimensions of an ideal "learning organisation"?}

The variables under investigation include the seven dimensions of learning organisation and organisational performance. The results showed that the dimensions evidencing the lowest mean scores were Empowerment and embedded system that is 3.59 and 3.57 respectively. The fact that embedded system held the lowest mean shows that staff members feel that their institutions are not doing enough to capture, maintain and share the knowledge learned. As suggested by Watkins and Marsick (2003) this is a worrying trend and the embedded system dimension is considered a point of reference to help the organisation to manoeuvre at times of high employees' turnover and market turbulences. In order to become "learning organisations", HE institutions should promote the culture of sharing knowledge throughout the organisation that would help to have an effective embedded system.

On the other hand, organisational performance showed the highest mean score of 3.90. Indeed, the data in Table 1 indicate that members of staff are not satisfied with the level of application of dimensions of learning organisation in their respective universities. The analyses of the means at $95 \%$ confidence level across other variables and factors showed a similar trend of low figures. Variations figures were higher in oldest participants (age over 60) with the lowest being in members between 31 to 40 years. Employees with experience in the job of less than 12 months had the highest scores as compared to employees with more experience. This therefore shows that duration of work experience also has an impact on organisational performance. Employees with more experience make decision that impact performance in the institutions as compared to those with less experience. This is in line with finding by Akhtar et al (2011) that staff members in universities look up to their managers before making major decisions instead of relying on their own knowledge.

\section{What dimensions of the learning organisation framework are associated with organisation performance?}

The present research shows that all the dimension of the learning organisation framework, apart from the inquiry and dialogue dimension had a positive effect on the performance of the universities. As explained by Hussein $e t$ al. (2014), inquiry and dialogue entail the acquisition of knowledge from others. This dimension was found to have the least effect on organisational performance of the studied universities in Saudi Arabia. This shows that HE institutions are poor in cultivating the spirit of acquiring knowledge among the staff members.

The current research found that system connection had the most substantial relationship with organisational performance (Variance Inflation Factor -VIF = 4.645) and universities that most frequently encouraged staff teams to think of opportunities and problems from a global perspective also score higher in organisational performance. In addition, data show that the institutions encourage the employees to enquire and look for solutions internally before they consider outsourcing.

System connection is the sixth dimension among the dimensions of learning organisation as drafted by Watkin 
and Marsick (2003). The findings in this paper show that most institutions have established strong connections with their environment. According to Senge (1990), organisations usually suffers from inertia and realises how hard it is to keep pace with a changing environment. As stated by Carter and Greer (2013) the more time an organisation takes to flow with the market changes, the fewer the option is for it to regain back its desired position. Having an effective system connection would help the organisation to capture and enhance organisation capability to be successful.

The present findings are in agreement with the research by Oh (2019) which found out that a system connection also had a mediating and positive impact on the relationship between Empowerment, continuous learning and organisational performance. An effective system connection also is considered as a base to clarify the bigger picture of the organisation (Sayed \& Edgar, 2019). This includes giving employees support, time, identification of skills for future tasks and open discussions to identify mistakes and reward for learning. The impact of system connection in the organisations like the public universities can be enhanced through activities such as on-site case study, seminars, trainings which help to enhance the organsation performance trough understanding main objectives of the organsation (Antonacopoulou et al., 2019; Sayed \& Edgar, 2019).

\section{To what extent the application of "learning organisation" is affected by demographic variables?}

The present results indicates that the education level attained the respondents is consistently the factor that was significant with all the dimension of organisational learning under investigation and organisational performance. It can be seen that employees holding $\mathrm{PhD}$ had higher statistical significance with all the dimension of organisational learning and organisational performance compared to those with master's degree.

The impact of education level on organisational performance is explained by Cappelli (2000) who argue that learned individuals have gained more cognitive capacity which they apply in the workplace. Senge (1994) adds that learning in organisations enhances strategic thinking and unity of aims.

According to Bhaskar \& Mishra (2017), most organisations use educational levels as the basis for selecting candidates with the skills needed in the organisation. Highly educated staff members are more likely to contribute more efficiently to noncore activities in the workplace as well.

A study assessing the trend of education in the US found that individuals completing both high school and college education had drastically improved from 1980 to 2006 by around 28\%. This leads to evidenced positive outcome and positive career outcomes including job mobility, development opportunities, increased job promotions and better salary levels. (Cappelli, 2000)

The education levels of employees have also been found to contribute significantly to organisational performance especially in times of turbulences. Highly educated workers have the tendency to be more creative in their behaviors at such times as compared to less educated workers. Another reason why education levels have positive correlation to organisational performance is because the highly education employees tend to engage in fewer counter-productive actions. Counterproductive actions and behaviors in the workplace include absenteeism, substance use in the workplace and work aggression.

\section{Conclusion and Recommendations}

The present research focused on the institutions of higher education in the Kingdom of Saudi Arabia. Universities are known to be the incubators of knowledge and the spearhead innovation and prosperity in a nation. The study findings provided insights of how the application of learning dimensions can lead to performance in the universities. Generally the learning organisation dimensions among the studied universities are moderate. The data on the dimensions studied shows that learning organisation is not applied to satisfactory levels.

As the literature review and study findings show, it is becoming increasingly important for institutions of higher education which are like many other modern organisations, to adopt learning orientation because it will lead to organisational success. The learning in an institution should not be expected to readily and naturally happen; therefore, efforts should be put into place to make it as a culture in the organisation. Parallel to other organisations, public institutions should implement learning organisations practices to ensure that set objectives are achieved. As has been discussed above, many studies recognise that learning organisations have a positive impact on organisational growth and performance.

Human resource developers in organisations are usually responsible for promoting opportunities for continuous learning. Organisational learning is largely important in the current job market where the individuals regularly hop between jobs and reserve what they know with the mentality that sharing what they know might cause a downfall to their success. It is the hope of the researcher that these study findings will push to identify that is not sufficient to rely on the continuous learning of a few individuals in the executive without building the institutions capacity to capture, inspire and share that knowledge. 
It is recommended that public universities go back to the drawing board and embrace the changes which will steer the institutions toward becoming an ideal learning organisation. Hence, the institutions should introduce change agents in different departments to examine the specific needs of the organisation and then accompany the organisation through the transformative change.

This present research identified that individual with higher educational levels tended to have a better understanding of the mechanisms leading to the establishment of a "learning organsation" than those less educated. In order to counteract this tendency, human resource managers should promote a comprehensive continuous learning policy within all job roles in the institution. This learning should then be captured and integrated into the existing structures and practices in ways that it can be easily accessed and shared by all members of the institution.

The various tools provided by the learning organisation framework can only be successfully implemented in any organisation if leaders and managers support them. In agreement with this Marsic \&Watkin (2003) and Sharifirad (2011) stated that strategic leadership acts as the mediators between what can be done and what is actually executed. It can be said that strategic leadership is a major driver for the organisations to determine their needs to use technology, information processing, number of individuals learning new skills and quality of services and programs to be in a competitive position. Learning programs therefore have to be supported by the strategic leadership so that the intended effects can be achieved.

\section{References}

Akhtar, S., Arif, A., Rubi, E., \& Naveed, S. (2011). Impact of Organizational Learning on Organizational Performance: Study of Higher Education Institutes. International Journal of Academic Research, 3(5), 327-331.

Al-Hemyari, Z. A. (2019). A knowledge management model for enhancing quality and performance of higher education institutions: insights from Oman. International Journal of Quality and Innovation, 4(1-2), 99-119. https://doi.org/10.1504/IJQI.2019.101435

Alkhathlan, K., Gately, D., \& Javid, M. (2014). Analysis of Saudi Arabia's behavior within OPEC and the world oil market. Energy Policy, 64, 209-225. https://doi.org/10.1016/j.enpol.2013.09.030

Al-Musali, M. A. K., \& Ku Ismail, K. N. I. (2014). Intellectual capital and its effect on financial performance of banks: Evidence from Saudi Arabia.Procedia-Social and Behavioral Sciences, 164, 201-207. https://doi.org/10.1016/j.sbspro.2014.11.068

Al-shehry, A. M. (2009). Transformation towards e-government in The Kingdom of Saudi Arabia: technological and organisational perspectives.

Alshuwaikhat, H. M., Adenle, Y. A., \& Saghir, B. (2016). Sustainability assessment of higher education institutions in Saudi Arabia. Sustainability, 8(8), 750. https://doi.org/10.3390/su8080750

Altbach, P., Reisberg, L., Salmi, J., \& Froumin, I. (Eds.). (2018). Accelerated universities: ideas and money combine to build academic excellence. BRILL. https://doi.org/10.1163/9789004366107

Antonacopoulou, E. P., Moldjord, C., Steiro, T. J., \& Stokkeland, C. (2019). The New "learning organisation". The Learning Organization. https://doi.org/10.1108/TLO-10-2018-0159

Argyris, C., Schon, D.A. (2011). Organizational Learning. Addison-Wesley.

Babbie, E., Wagner III, W. E., \& Zaino, J. (2018). Adventures in social research: Data analysis using IBM SPSS statistics. Sage Publications.

Barker, R. T., \& Camarata, M. R. (1998). The role of communication in creating and maintaining a learning organisation: Preconditions, indicators, and disciplines. The Journal of Business Communication (1973), 35(4), 443-467. https://doi.org/10.1177/002194369803500402

Bhaskar, A. U., \& Mishra, B. (2017). Exploring relationship between learning organisations dimensions and organisational performance. International Journal of Emerging Markets. https://doi.org/10.1108/IJoEM-01-2016-0026

Bland, J. M., \& Altman, D. G. (1997). Statistics notes: Cronbach's alpha. Bmj, 314(7080), 572. https://doi.org/10.1136/bmj.314.7080.572

Boguslavskii, M. V., \& Neborskii, Y. V. (2016). Development of the university education in the context of globalisation. In SHS Web of Conferences (Vol. 29, p. 01011). EDP Sciences. https://doi.org/10.1051/shsconf/20162901011

Cappelli, P. (2000). Examining the incidence of downsizing and its effect on establishment performance (No. w7742). National bureau of economic research. https://doi.org/10.3386/w7742 
Carter, S. M., \& Greer, C. R. (2013). Strategic Leadership: Values, Styles, and Organizational Performance. Journal of Leadership \& Organizational Studies, 20(4), 375-393. https://doi.org/10.1177/1548051812471724

Cosgrove, W. J., \& Loucks, D. P. (2015). Water management: Current and future challenges and research directions. Water Resources Research, 51(6), 4823-4839. https://doi.org/10.1002/2014WR016869

Dervitsiotis, K. N. (1998). The challenge of managing organisational change: Exploring the relationship of re-engineering, developing learning organisations and total quality management. Total Quality Management, 9(1), 109-122. https://doi.org/10.1080/0954412989306

Fernandez, S., \& Moldogaziev, T. (2013). Employee empowerment, employee attitudes, and performance: Testing a causal model. Public Administration Review, 73(3), 490-506. https://doi.org/10.1111/puar.12049

Field, L. (1997). Impediments to Empowerment and learning within organisations. The Learning Organization. https://doi.org/10.1108/09696479710170842

Fillion, G., Koffi, V., \& Ekionea, J. P. B. (2015). Peter Senge's learning organisation: A critical view and the addition of some new concepts to actualise theory and practice. Journal of Organizational Culture, Communications and Conflict, 19(3), 73.

Fleiss, J. L., Levin, B., \& Paik, M. C. (2013). Statistical methods for rates and proportions. john wiley \& sons.

Geiger, R. L. (2019). American Higher Education Since World War II: A History (Vol. 116). Princeton University Press. https://doi.org/10.2307/j.ctv9hvtbz

Goh, S. C. (1998). Toward a learning organisation: The strategic building blocks. SAM Advanced Management Journal, 63, 15-22.

Goldratt, E. M. (1990). Theory of constraints. Croton-on-Hudson: North River.

Goyal, A. M. (2013). Impact of capital structure on performance of listed public sector banks in India. International journal of business and management invention, 2(10), 35-43.

Hamann, P. M., Schiemann, F., Bellora, L., \& Guenther, T. W. (2013). Exploring the dimensions of organisational performance: A construct validity study. Organizational Research Methods, 16(1), 67-87. https://doi.org/10.1177/1094428112470007

Hazelkorn, E. (2013). World-class universities or world-class systems? Rankings and higher education policy choices. Rankings and accountability in higher education: Uses and misuses, 71-94.

Hilal, K. T., Scott, S., \& Maadad, N. (2015). The Political, Socio-Economic and Sociocultural Impacts of the King Abdullah Scholarship Program (KASP) on Saudi Arabia. International Journal of Higher Education, 4(1), 254-267. https://doi.org/10.5430/ijhe.v4n1p254

Hung, R. Y. Y., Yang, B., Lien, B. Y. H., McLean, G. N., \& Kuo, Y. M. (2010). Dynamic capability: Impact of process alignment and organisational learning culture on performance. Journal of World Business, 45(3), 285-294. https://doi.org/10.1016/j.jwb.2009.09.003

Hussein, N., Mohamad, A., Noordin, F., \& Ishak, N. A. (2014). Learning organisation and its effect on organisational performance and organisational innovativeness: A proposed framework for Malaysian Public Institutions of Higher Education. Procedia-Social and Behavioral Sciences, 130(2014), 299-304. https://doi.org/10.1016/j.sbspro.2014.04.035

Hvidt, M. (2013). Economic diversification in GCC countries: Past record and future trends.

Imam, A., Abbasi, A. S., Muneer, S., \& Qadri, M. M. (2013). Organisational culture and performance of higher educational institutions: The mediating role of individual readiness for change. European Journal of Business and Management, 5(20), 23-34.

Islam, S. I. (2014). Saudi women: Opportunities and challenges in science and technology. Education Journal, 3(2), 71-78.

Karakas, F. (2010). Spirituality and performance in organisations: A literature review. Journal of business ethics, 94(1), 89-106. https://doi.org/10.1007/s10551-009-0251-5

Khan, M. K., \& Khan, M. B. (Eds.). (2020). Research, Innovation and Entrepreneurship in Saudi Arabia: Vision 2030. Routledge. https://doi.org/10.4324/9781351040020

Kim, J., Egan, T., \& Tolson, H. (2015). Examining the dimensions of the learning organization questionnaire: a review and critique of research utilizing the DLOQ. Human resource development review, 14(1), 91-112. https://doi.org/10.1177/1534484314555402

Laeeque, S. H., \& Babar, S. F. (2015). Learning organisation as a strategy to improve performance of Pakistani 
hospitals.

Marlow, S. L., Lacerenza, C. N., Paoletti, J., Burke, C. S., \& Salas, E. (2018). Does team communication represent a one-size-fits-all approach?: A meta-analysis of team communication and performance. Organisational Behavior and Human Decision Processes, 144, 145-170. https://doi.org/10.1016/j.obhdp.2017.08.001

Marsick, V. J., \& Watkins, K. E. (2003). Demonstrating the value of an organization's learning culture: the dimensions of the learning organization questionnaire. Advances in developing human resources, 5(2), 132-151. https://doi.org/10.1177/1523422303005002002

Mbuthia, R. N. (2018). Learning Organization Dimensions And Organizational Performance Of Commercial Banks In Kenya: Survey Of Commercial Banks In Ongata Rongai Township (Doctoral dissertation, School Of Business, Kenyatta University).

Nielsen, P., Rasmussen, P., \& Kuo, T. H. (2011). How to improve organisational performance through learning and knowledge? International Journal of Manpower.

Oh, S. Y. (2019). Effects of organisational learning on performance: the moderating roles of trust in leaders and organisational justice. Journal of Knowledge Management. https://doi.org/10.1108/JKM-02-2018-0087

Onwuegbuzie, A. J., Witcher, A. E., Collins, K. M., Filer, J. D., Wiedmaier, C. D., \& Moore, C. W. (2007). Students' perceptions of characteristics of effective college teachers: A validity study of a teaching evaluation form using a mixed-methods analysis. American Educational Research Journal, 44(1), 113-160. https://doi.org/10.3102/0002831206298169

Othayman, M. B., Meshari, A., Mulyata, J., \& Debrah, Y. (2020). The Challenges Confronting the Delivery of Training and Development Programs in Saudi Arabia: A Critical Review of Research. American Journal of Industrial and Business Management, 10(09), 1611. https://doi.org/10.4236/ajibm.2020.109103

Phusavat, K., Comepa, N., Sitko-Lutek, A., \& Ooi, K. B. (2011). Interrelationships between intellectual capital and performance. Industrial Management \& Data Systems. https://doi.org/10.1108/02635571111144928

Ponnuswamy, I., \& Manohar, H. L. (2016). Impact of learning organization culture on performance in higher education institutions. Studies in Higher Education, 41(1), 21-36. https://doi.org/10.1080/03075079.2014.914920

Saifulhafizi, H. (2014). The influence of learning organisation towards the performance: A study on small and medium enterprise (SME) of manufacturing firms in Johor Bahru, Johor (Doctoral dissertation, Universiti Utara Malaysia).

Salau, A. O., \& Ahmad, A. C. (2016). Audit fees, corporate governance mechanisms, and financial reporting quality in Nigeria. DLSU Business \& Economics Review, 26(1), 122-135.

Sayed, S. S. S. A., \& Edgar, D. (2019). The role of leadership competencies in supporting the Al Nahda University for becoming a learning organisation: a new qualitative framework of the DLOQ. International Journal of Business Administration, 10(2). https://doi.org/10.5430/ijba.v10n2p43

Senge, P. (2004). Five disciplines. New York, NY: Doubieday.

Senge, P. M. (1990). The art and practice of the learning organization.

Senge, P. M. (2006). The fifth discipline: The art and practice of the learning organisation. Broadway Business.

Senge, P. M. (2014). The fifth discipline fieldbook: Strategies and tools for building a learning organisation. Crown Business.

Senge, P. M. et al. (1994). The Fifth Discipline Fieldbook: Strategies and Tools for Building a Learning Organization. New York: Doubleday.

Sharifirad, M. S. (2011). The dimensions of learning organization questionnaire (DLOQ): A cross-cultural validation in an Iranian context. International Journal of Manpower, 32(5-6), 661-676. https://doi.org/10.1108/01437721111158251

Shepherd, D. A., \& Gruber, M. (2020). The Lean Startup Framework: Closing the Academic-Practitioner Divide. Entrepreneurship Theory and Practice, 1042258719899415. https://doi.org/10.1177/1042258719899415

Smith, L., \& Abouammoh, A. (2013). Higher Education in Saudi Arabia. Netherlands: Springer. https://doi.org/10.1007/978-94-007-6321-0

Song, J. H., Chai, D. S., Kim, J., \& Bae, S. H. (2018). Job performance in the learning organisation: The mediating impacts of self-Efficacy and work engagement. Performance Improvement Quarterly, 30(4), 
249-271. https://doi.org/10.1002/piq.21251

Song, J. H., Joo, B., \& Chermack, T. J. (2009). The dimensions of learning organisation questionnaire (DLOQ): A validation study in a Korean context. Human Resource Development Quarterly, 20(1), 43-64. https://doi.org/10.1002/hrdq.20007

Soon, T. T., \& Zainol, F. A. (2011). Knowledge management enablers, process and organisational performance: evidence from Malaysian enterprises. Asian Social Science, 7(8), 186. https://doi.org/10.5539/ass.v7n8p186

Yang, B., Watkins, K. E., \& Marsick, V. J. (2004). The construct of the learning organisation: Dimensions, measurement, and validation. Human resource development quarterly, 15(1), 31-55. https://doi.org/10.1002/hrdq.1086

Yeravdekar, V. R., \& Tiwari, G. (2016). Internationalisation of higher education in India. SAGE Publications India.

\section{Copyrights}

Copyright for this article is retained by the author(s), with first publication rights granted to the journal.

This is an open-access article distributed under the terms and conditions of the Creative Commons Attribution license (http://creativecommons.org/licenses/by/4.0/). 